\title{
Project-oriented system of professional training of university teachers
}

\author{
L.A. Turchina ${ }^{1 *}$, N.B. Romaeva ${ }^{2}$, and L.I. Abbasova ${ }^{3}$ \\ ${ }^{1}$ V.I. Vernadsky Crimean Federal University, Simferopol, Russia \\ 2 Stavropol Krai Institute for the development of education, training and retraining of workers \\ education, Stavropol, Russia \\ ${ }^{3}$ State Budget Educational Institution of Higher Education of the Republic of Crimea Crimean \\ Engineering and Pedagogical University the name of Fevzi Yakubov, Simferopol, Russia
}

\begin{abstract}
The article examines the complex structure of such a complicated educational segment as the system of advanced training for teachers of a modern university. The place and role of such a system in the structure of professional culture and the formation of a specialist's professionalism is determined. The key problems and crisis points that exist within the framework of this object are identified. At the same time, the main mechanisms for improving and modernizing of the system of improving pedagogical qualifications are identified, the most important of which is the project-oriented training. Within the framework of this definition, the essence and specificity of the project-oriented approach in general and in relation to the system of advanced training of a modern teacher in particular are determined. The main criteria, based on which these systems cross and complement each other, are highlighted. The study performs a theoretical and practical potential that can replenish the existing pedagogical scientific base, and also enters a new stage of theoretical understanding of the problem of improving the professional qualifications of university teachers. This article is based on both theoretical and practical foundations, expressed in the form of an analysis of authoritative scientific sources and in the results of the survey. At the same time, the questionnaire has become a key research method, since it included a survey of more than 200 teachers undergoing regular training in advanced training systems, due to which this work raises new questions necessary for a comprehensive intensification of educational processes in this direction. This method is one of the most effective and promising methods of scientific research.
\end{abstract}

\section{A problem statement}

The development of the educational industry involves the parallel development of all its constituent elements and the personal, professional and creative growth of the subjects interacting within it. The education system, being an important social institution, depends precisely on the social potential - people and their interaction. In this regard, we can say that it needs the most intelligent and competent specialists who are able to organize and

*Corresponding author: ipcs-profped@yandex.ru 
control all the processes that depend on their activities. Thus, the problem of the need for constant correspondence of teachers and managers in the field of education to current trends is being formed, which is reflected in other social institutions, developing in a single sociocultural space of our country. Only relevant, mobile and able to the quick and prompt response to emerging difficulties specialists constitute the main potential of this industry. Based on this, native and foreign researchers face the problem of the need to conduct regular events to improve the qualifications of teachers of a modern university using the maximum possible tools and technologies, as well as with an orientation towards the leading project-oriented approach.

\subsection{The objective of the work}

The above-mentioned problem is reflected in the works of many Russian researchers, including L.A. Bokov, A.F. Pozdeeva, O.M. Zamyatina, M.A. Soloviev, S.M. Vishnyakova, E.A. Vlasov, A.L. Gavrikov, N.P. Litvinova, S.A. Domracheva, E.V. Ignatovich, N.G. Kalinnikova, A.G. Kasprzhak, M.V. Klarin, A.V. Komarova, N.E. Kopytova, L.N. Makarova, V.A. Slastenin, S.A. Pisareva, V.A. Seleznev, V.A. Fedorov, I.A. Sharshov, L.F. Shakurova and others.

The works of these scientists formed the basis of this study and became a significant stage in the process of comprehending the above-described problems. They made it possible to replenish the basis with the necessary theoretical and practical data, which allow us to actualize the need to solve the described problem and come to a single pedagogical consensus.

\section{Materials and the results of the research}

To implement the most effective and comprehensive research, we have identified a chain of tasks leading to the formation of a global aim of all the work. These tasks include:

- the identification of the specifics of the project-oriented system, as well as the specifics of the system of advanced training for teachers, within which it is being implemented;

- the identification of the problems and potential for introducing of such an approach into the process of retraining and additional training of modern university teachers;

- the conducting of an analytical study (in the form of a questionnaire) underlying the disclosure of the topic;

- the research of the experience of leading teachers and other scientists involved in the development of this topic;

- the determination of the most effective and ineffective elements of the currently existing project-oriented approach used in the system of professional development of teachers.

Based on the above-described tasks, the purpose of this study is to identify and consider the essence and specifics of the project-oriented system of advanced training for university teachers at the present stage of development of the system of additional education.

A special place in the system of advanced training of teachers of a modern university is given to the problem of determining an effective model for advanced training of such specialists who are ready not only to carry out professional activities, but also to create new, conceptually significant systems, flexible and mobile, capable of optimizing the educational process and to modernize educational environment [3]. Such a system must necessarily be based on making projects and searching activities, which consist in regular research and publication of scientific papers related to the solution of certain educational problems. Thus, the system of advanced training involves not only the improvement of 
professional skills required directly in organizational and administrative activities, but also in individual scientific activities [12].

There is a certain system of foundations for organizing a project-oriented system of advanced training, which includes:

- the project-based learning strategy that aims to the formation of a complete and integral system of projecting skills among teachers, aimed not only at the implementation of educational and pedagogical projects, but also at their application in everyday life in the framework of solving certain problem situations [7];

- the strategy of situational learning, the basis of which is the case method, which includes the technology of creating such a situation that has already happened with one of the teachers, or can potentially happen, and which requires an immediate and professional solution;

- the strategy of reflective learning, aimed at the formation and development of the teacher's skills of an analytical and reflective nature, consisting in the assessment and objective criticism of their own activities, on the basis of which there is an opportunity to correct their own professional route [10];

- the strategy of experimental learning, which consists in conducting experiments of a scientific and practical nature, capable of revealing a certain professional and creative potential of a teacher.

Some native researchers believe that such a strategy for the development of a system of advanced training for teachers is able to minimize the risks of teachers' inconsistency with current tendencies and trends in the global world [6].

At the same time all these strategies should be applied to practicing teachers who are capable of improving their own activities and who want to correspond to new criteria. In other words, the factor of motivation and involvement in the process of professional development of teachers is extremely important here [11]. Very often representatives of traditional pedagogy deny the need for advanced training, referring to the classic dogmas of traditional pedagogy, which are considered to be the basis of the foundations, the primary of pedagogical activity. Very often such representatives do not take into account the needs of modern students, society, the environment into which a senior student enters after graduation [1]. The development of exactly such teachers in a new way is the main direction of the impact of the advanced training system, since, on the one hand, they need it more than anyone else, and on the other hand, they have the necessary fundamental basis on which it is possible to arrange new knowledge in layers and to form skills of a new order.

Besides, it is important to pay attention to the stages of organizing a project-oriented system of professional development of teachers, since this will allow us to deep into the study of this topic and to understand the specifics of the system of advanced training, which will allow us to focus on the existing problems in this area and to identify certain risks [19].

In general a project-oriented system of advanced training for teachers is usually understood as such an educational space, within which the existing experience of teachers is transformed into a new, more perfect and relevant experience of independent implementation of pedagogical activities, as well as self-realization in a professional environment $[2 ; 4 ; 5 ; 6 ; 8 ; 9 ; 13]$. It is important to understand that such a system is aimed primarily at improving of the existing systems, and not at their full replacement. The training of specialists should be carried out not so much within the framework of their implementation of new types of activity, but within the framework of the perception and formation of innovative products that can activate the mental activity of students, involve them in the learning process, maximize the process of professional training of future specialists and improve the already existing educational system.

It is important to explain to the teacher that he needs to develop his own creative component, to express his individuality and creativity [9]. This, according to many 
researchers, lies at the heart of a harmoniously developed personality of a professional in any field of activity. Earlier we mentioned the need to focus on research activities on the part of teachers. We would like to point out the importance of such events. The fact is that many practicing teachers start to apply certain technologies directly in practical activities, without having researched and analyzed their capabilities, hidden potentials and risks beforehand. It leads to a violation of educational integrity and fragmentation of knowledge, which affects students negatively. In this regard it is important to actualize the research potential of pedagogical work, which can become an important help not only for further research, but also for practical activities [2].

According to the researchers, the project-oriented system of professional development of teachers is based on the key ideas of the system-activity and personality-developmental approaches. They make it possible to differentiate and update different types of activities of modern teachers, depending on their abilities and capabilities. Together these approaches constitute an important system aimed at the formation of positive experience, creativity, personal opinion in the course of educational activities [7]. In addition, through such a tandem, the teacher forms the basis of motivation not only in relation to the implementation of direct training and education of the younger generation, but also in relation to selfimprovement in various activities.

The motivational component allows the teacher to carry out continuous education, which today is one of the most urgent areas of human activity to improve their abilities. A specialist who turns to the system of continuous education is guaranteed to remain among the most relevant and significant subjects for the education system and the system of ensuring the educational process [14].

Based on this specificity, many researchers believe that the project-oriented system of professional development of teachers is of a complex multi-level nature and consists of several components:

- the relevance of the content and the expedient fullness of the advanced training program, which is aimed not at the transferring of new knowledge, but at the formation of a complex of conditions for the development and at the formation of a complex of professional experience of teachers, most characteristic of modern pedagogical science and practice;

- the use of modern teaching methods in the advanced training system, which can be further used by teachers in their own activities. It is important to note here that today a wide variety of technologies are actively used to enhance the attention and creative activity of a person. For the development of a teacher, these aspects are extremely important and formative for the system of professional competence. It is important not only to acquaint the teacher with such technologies, but also to stimulate his usage of them in practice, the development of new technologies based on existing ones and on the modernization of those already used [5];

- the use of modern technical and digital teaching aids in such a process, which make it possible to acquaint teachers with the new and most relevant system of material and technical equipment of the educational process [16].

Based on the foregoing, the last aspect is especially interesting for us, since many students note the insufficient awareness of teachers in the methods and tools of the digital environment [17]. This is an extremely important point, since digitalization, which has reached a certain stage of development at the moment, dictates new rules for interaction in the socio-cultural space. In this regard, a modern teacher needs to navigate the system of information and communication technologies and apply them actively in their own activities.

In the course of this study special attention was paid to conducting a questionnaire survey of teachers who have passed the project-oriented refresher courses, the results of 
which can be found in the table below. The criterion of satisfaction with the acquired level of certain competencies, which has a direct impact on the implementation of professional activities, was chosen as the main criterion for assessing the advanced training system. In this regard the teachers were presented with a list of issues related to the quality of their professional competencies acquired in the course of project-oriented professional development. Next, we will consider the results obtained and explain this state of affairs.

Based on the results of the above-described, we can conclude that not all of the acquired or improved systems of teachers' competencies are satisfactory. The fact is that there is a subjective factor that illustrates the teachers' own attitude to their own competencies. In this regard the results of the study are somewhat dualistic and can be interpreted in different ways by different researchers.

The most satisfactory were the competencies in the field of motivation for learning activity (63.7\%); in the field of providing an information basis for activities $(62.7 \%)$; in the field of pedagogical decision making $(75 \%)$; in the field of organizing educational activities $(68.5 \%)$; in the field of independent organization of their own activities $(59.5 \%)$.

An important role here is played by the field of pedagogical decision making, which directly depends on the project orientation of the entire advanced training system, since elements of projecting stimulate teachers to develop and resolve problem situations independently (case method), to find options for solving crisis issues, etc.

The lowest indicators of satisfaction were found in competencies in the field of personal qualities $(72 \%)$ and in the field of setting goals and objectives of pedagogical activity $(69 \%)$.

Table 1. The degree of satisfaction of teachers who regularly take advanced training courses with acquired competencies (\%).

\begin{tabular}{|l|l|l|l|l|}
\hline & $\begin{array}{l}\text { Absolute } \\
\text { satisfaction }\end{array}$ & $\begin{array}{l}\text { Partial } \\
\text { satisfaction }\end{array}$ & $\begin{array}{l}\text { Partial } \\
\text { dissatisfaction }\end{array}$ & $\begin{array}{l}\text { Absolute } \\
\text { dissatisfaction }\end{array}$ \\
\hline $\begin{array}{l}\text { Competence in the } \\
\text { field of personality } \\
\text { traits }\end{array}$ & 19.8 & 8.2 & 31.2 & $\mathbf{4 0 . 8}$ \\
\hline $\begin{array}{l}\text { Competence in the } \\
\text { field of setting goals } \\
\text { and objectives of } \\
\text { pedagogical activity }\end{array}$ & 14.5 & 16.5 & 24.3 & $\mathbf{4 4 . 7}$ \\
\hline $\begin{array}{l}\text { Competence in the } \\
\text { field of motivating } \\
\text { learning activities }\end{array}$ & 12.5 & $\mathbf{5 1 . 2}$ & 30.8 & 5.5 \\
\hline $\begin{array}{l}\text { Competence in the } \\
\text { field of providing } \\
\text { information basis for } \\
\text { activities }\end{array}$ & $\mathbf{3 2 . 9}$ & 29.8 & 26.5 & 12.6 \\
\hline $\begin{array}{l}\text { Competence in the } \\
\text { field of pedagogical } \\
\text { decision making }\end{array}$ & $\mathbf{4 0 . 1}$ & 34.9 & 16.5 & 8.5 \\
\hline $\begin{array}{l}\text { Competence in the } \\
\text { field of organizing } \\
\text { educational activities }\end{array}$ & $\mathbf{4 1 . 6}$ & 26.9 & 15.4 & 16.5 \\
\hline $\begin{array}{l}\text { Competence in the } \\
\text { field of independent } \\
\text { organization of their } \\
\text { own activities }\end{array}$ & $\mathbf{4 0 . 3}$ & 29.2 & 10.3 & 10.2 \\
\hline
\end{tabular}

In many respects this state of affairs is characterized by a rather low motivation of many teachers who are not able to cultivate independently the personal qualities necessary for 
organizing of the educational process and for its control. As a rule, it refers to young teachers who have not learned to own and manage their own internal resources to the full extent. Besides, the low indicator in the field of pedagogical goal-setting illustrates a new problem in the advanced training system - the inability of many teachers to follow the existing stages. It is to solve these problems it is necessary to apply the project-oriented principle, according to which (thanks largely to project technologies) the teacher can learn to follow the stages of effective projecting: planning, forecasting, problematization and goal-setting. The lack of such skills can negatively affect not only the teacher himself and his personality, but also the professional activity, the inability to solve problems and to implement the correct conceptual goal setting.

\section{Conclusions}

Appropriate and purposeful disclosure of pedagogical professional potential among teachers of a higher educational institution is one of the most important tasks of the modern system of supporting of professional educational activity. Today it is especially important to pay attention to the formation of not only general, global competencies among teachers, but also to the formation of special, narrowly focused competencies. To do this, it is necessary to carry out the multi-stage training of teachers first through the vocational guidance training, then through the higher professional, then through the gradually raising qualifications and, finally, through the continuous education. Each link in this chain is responsible for the formation and development of individual competencies and aspects of pedagogical activity, without which it is impossible to ensure the effectiveness and intensity of the learning process.

A special role in this chain is played by the system of advanced training of university teachers through the involvement of active project-oriented technologies. Such a system is a special educational and professional space that influences the transformation of the existing pedagogical experience. It is such a system, in our opinion, combining successfully theoretical and practical orientation at the same time, is able to provide the teacher with important resources and relevant knowledge, with the ways of transforming his own experience and with the carrying out of independent activities.

\section{References}

1. L.A. Bokov, A.F. Pozdeeva, O.M. Zamyatina, M.A. Soloviev, Project-oriented educational technologies in the training of elite specialists, Int. J. of Applied and Fundamental Research, 1, 105-109 (2014)

2. S.M. Vishnyakova, Professional education, p. 538 (Moscow, 1999)

3. E.A. Vlasov, Advanced training of workers in the conditions of the educational and production complex: abstract of dis. ... cand. ped. sciences, p. 24 (Volgograd, 2007)

4. A.L. Gavrikov, N.P. Litvinova, Adult education in the XXI century: The new role of universities in its development, p. 174 (Moscow: publishing House of the research center for quality problems of training specialists, 2001)

5. S.A. Domracheva, Socio-pedagogical projecting as one of the modern technologies for training a professional in the education system, Prospects for Science, 11 (50), 24$28(2013)$

6. S.A. Domracheva, Training university teachers in a project-oriented approach as one of the conditions for the development of a modern university, Bulletin of the Mari State University, 3 (2017) 
7. E.V. Ignatovich, Actual directions of advanced training of scientific and pedagogical workers of the university, Modern problems of science and education, 1 (2013)

8. N.G. Kalinnikova, Continuous pedagogical education as a paradigm, Knowledge. Understanding. Skill, 3, 186-189 (2005)

9. A.G. Kasprzhak, Formation of an innovative resource of pedagogical personnel in the education system through the development of a system of advanced training, p. 288 (Moscow: University book, 2007)

10. M.V. Clarin, Innovative teaching models: Research of world experience, p. 640 (Moscow: Luch, 2018)

11. A.V. Komarova, Project-oriented knowledge management: criteria for classifying projects, Russian Economic Internet Journal, 4 (2010)

12. N.E. Kopytova, L.N. Makarova, Professional development of university teachers: state and problems, Bulletin of TSU, 4 (2012)

13. L.N. Makarova, I.A. Sharshov, Competence-developing model of advanced training of pedagogical personnel, Education and Society, 4 (69), 14-17 (2011)

14. Educational strategies and learning technologies in the implementation of the competence-based approach in teacher education, taking into account humanitarian technologies, p. 108 (Publishing house of the RSPU after. A.I. Herzen, 2008)

15. I.V. Nosaeva, Pedagogical conditions for the formation of research culture of students at the initial stage of education: dis. ... cand. ped. sciences, p. 183 (Saint Petersburg, 2001)

16. V.A. Seleznev, Project-oriented system of professional development of teachers, Scientific support of the personnel development system, 3 (36) (2018)

17. V.A. Fedorov, Professional pedagogical education: theory, empiricism, practice, p. 330 (Yekaterinburg: Ural state professional pedagogical University press, 2001)

18. L.F. Shakurova, Improving the qualifications of teaching staff as a condition for the implementation of the education strategy, Web resource, p. 20 (Institute of education development of the Republic of Bashkortostan, 2019)

19. I.A. Sharshov, L.N. Makarova, Problematic aspects of professional development of scientific and pedagogical personnel, Bulletin of the Tambov University, 10 (90), 7-11 (2010) 